\title{
EL VERSO INSTRUMENTAL ENTRE LA NUEVA ESPAÑA Y EL MÉXICO INDEPENDIENTE
}

\author{
INSTRUMENTAL VERSES BETWEEN THE NEW SPAIN VICEROYALTY \\ AND THE INDEPENDENT MEXICO
}

\author{
Jazmín Rincón Serratos \\ Universidad Nacional Autónoma de México \\ jazars@yahoo.com \\ ORCID iD: https://orcid.org/0000-0003-0398-4263
}

\begin{abstract}
Resumen
Los versos instrumentales y orquestales son tipologías con escritura idiomática para instrumentos usadas, al igual que los versillos organísticos, para reemplazar -en alternatim - versos cantados de salmos, himnos, o cánticos, según la celebración del Año Litúrgico. Aunque encontramos sus antecedentes y un desarrollo similar de dicho género en Europa, en el presente artículo, mediante un análisis histórico-contextual y discursivo de los juegos de versos pertenecientes a la generación de músicos de la Catedral de México que vivieron la época transicional entre la Nueva España y el México Independiente, se expondrán diversos aspectos que provocaron que el verso instrumental se volviese con el tiempo una tradición local, y con esto, en el gran protagonista de tipologías bipartitas en los archivos mexicanos de catedrales e iglesias pequeñas.
\end{abstract}

\section{Palabras clave}

Verso instrumental, versillos, Nueva España, México Independiente, Catedral de México, liturgia, Ilustración, colonización.

Aproximadamente en el año de 1748, Ignacio Jerusalem y Stella $(* 1707 ; \uparrow 1769)$ compuso los primeros versos con escritura idiomática para instrumentos sobrevivientes en la Catedral de México, y así, trazó una variante en la tradición oral de la música que había llegado con la vieja práctica alternatim de la liturgia: la improvisación de versillos ${ }^{1}$. No obstante, a pesar de que los

1 Esto se debe, como ya lo he expuesto anteriormente [RINCÓN (2014): 95-126], a que el compositor, de origen italiano, fue el primer maestro de capilla en la Catedral de México que introdujo composi-

(C) 2018 CSIC. Este es un artículo de acceso abierto distribuido bajo los términos de una licencia de uso y distribución Creative Commons Attribution 4.0 International (CC BY 4.0).

Cómo citar este artículo/Citation: Rincón Serratos, J. (2018). El verso instrumental entre la nueva España y el México independiente. Anuario Musical, 73 : 201-214. doi: http://dx.doi.org/10.3989/redc.2018.73.14

\begin{abstract}
Instrumental and orchestral verses are typologies of idiomatic writing for instruments used, as well as the organ versets, to replace -in alternatim- psalms verses, hymns, or chants in accordance to celebrations during the Liturgical Year. We find the antecedents of the genre and a similar development in Europe. Through a historical-contextual and a discursive analysis of the verses that belong to the generation of musicians of the Cathedral of Mexico who lived during the transition from New Spain to independent Mexico, this article examines several aspects that caused the instrumental verse to become, through time, a local tradition, and thus the main protagonist of bipartite typologies in the Mexican archives of cathedrals and small churches.
\end{abstract}

\section{Key words}

Instrumental verse, versets, New Spain, independent Mexico, Cathedral of Mexico, liturgy, Illustration, colonization.

versos instrumentales de Jerusalem se importaron a otras iglesias novohispanas y se interpretaron hasta épocas tan tardías como la misma culminación de la música en el templo, dicho maestro de capilla no fue del todo el responsable de que los versos instrumentales se convirtiesen en una tradición local. De hecho, sus in-

ciones en estilo galante con escritura idiomática para instrumentos, las cuales están emparentadas con la ópera, los conservatorios emergentes y la música italianizada que empezó a surgir en la burguesía europea como síntoma del llamado "movimiento de la Ilustración" que influyó fuertemente en toda la cultura occidental. 
mediatos sucesores a cargo de la capilla de la Catedral de México, Mateo Tollis della Rocca (1769-1780), Martín Bernárdez Rivera (1781-1791) y Antonio de Juanas (1762/63-después de 1816) no recurrieron a este género musical, por lo que cabe preguntarse: ¿Acaso alguien como Antonio Juanas, por ejemplo, consideraba que al no ser tipologías tradicionales, los versos para conjuntos de instrumentos no eran suficientemente necesarios para la liturgia?

Son los contemporáneos del violinista José Manuel Delgado (*1747; †1819), cuando el mismo Juanas era maestro de capilla (de 1791 a 1814), quienes convirtieron la iniciativa de Jerusalem en una tradición novohispana e impulsaron estas tipologías hacia el México
Independiente. Por tanto, a continuación expondré el contexto y el lenguaje sincrético que presentan los versos para instrumentos de aquellos músicos de la Catedral de México que, además de haberse formado en la ciudad de Valladolid (hoy Morelia, Michoacán), vivieron esta época transicional: José Manuel Delgado, José Mariano Mora (*1748; †1792), y José Manuel Aldana (*1758; †1810). Además, disertaré sobre cómo el transplante y la descontextualización de un género que se remonta a la tradición del contrapunto imitativo y la improvisación en Europa produjo que éste se convirtiese en el caso más paradigmático al respecto de géneros musicales usados y amoldados a la liturgia novohispana y mexicana.

\begin{tabular}{|c|c|c|c|c|}
\hline Compositor & $\begin{array}{l}\text { No. } \\
\text { de ver. }\end{array}$ & Título que aparece en el manuscrito & Sig. & $\begin{array}{c}\text { Folios / } \\
\text { Imágenes }\end{array}$ \\
\hline 1. José Manuel ALDANA & 6 & $\begin{array}{l}\text { Versos de quinto tono con / Violines, Clarinetter, Trompas / Bajo y Timbales } \\
\text { / por / Manuel Aldana / Del Repertorio de Ygnacio (Yujeque?) / Cpta. A. } \\
\text { Guerrero. }\end{array}$ & A0685 & $23 / 23$ \\
\hline 2. José Manuel ALDANA & 6 & $\begin{array}{l}\text { Organo } 1^{\circ} \text { Obligado / los Versos a Grande Orquesta comptos. / por Dn. José } \\
\text { Aldana } \\
\text { No. } 1, \text { pp. } 18, \text { Re }\end{array}$ & A0686 & $67 / 62$ \\
\hline 3. José Manuel ALDANA & 6 & $\begin{array}{l}\text { Versos ler tono, con Vs / Obs. Tromps.y Baso y Timbales / Comptos. pr. Dn. } \\
\text { Jose Aldana } \\
\text { No. } 2,803 \text { pp. } 10, \text { Re menor }\end{array}$ & A0687 & $22 / 21$ \\
\hline 4. Manuel DELGADO & 6 & $\begin{array}{l}\text { Verso de primo tono No. } 16 \text { P.M.D } \\
\text { Do menor }\end{array}$ & A0748 & $32 / 32$ \\
\hline 5. Manuel DELGADO & 5 & Juego de vers para 8vo To. P.M.D & $\mathrm{A} 0750$ & $14 / 14$ \\
\hline 6. Manuel DELGADO & 6 & $\begin{array}{l}\text { Juego de vers / no. } 4 \text { / para segundo tono / con oboes. y Tromps. } \\
\text { No. } 14 \text {, Son 9pp., Mi menor }\end{array}$ & A0751 & $20 / 20$ \\
\hline 7. Manuel DELGADO & 7 & $\begin{array}{l}\text { Juego tercero. / Vers.s. p. Prim.o tono / Tromps. y oboess. adlibtm. } \\
\text { No. 13, Son } 7 p p ., \text { Re menor }\end{array}$ & A0752 & $16 / 16$ \\
\hline 8. Manuel DELGADO & 5 & $\begin{array}{l}\text { Versos de } 1^{\circ} \text { tono No. } 13 \text { P.M. Delg. } \\
\text { N. } 2 \text {, Son } 12 \text { pp. Re menor }\end{array}$ & A0753 & $32 / 31$ \\
\hline 9. Manuel DELGADO & 7 & No. 11 Juego IV. No. 16 Segundo tono & A0754 & $10 / 10$ \\
\hline 10. Manuel DELGADO & 6 & $\begin{array}{l}\text { Versos para } 6^{\circ} \text { tono / no. } 1 \text { / a gran orq.ta. / P. M.D } \\
\text { No } 7 \text {, Son 8pp, Mi mayor }\end{array}$ & A0755 & $28 / 27$ \\
\hline 11. Manuel DELGADO & 5 & $\begin{array}{l}\text { Juego quinto / de / Versos p. 6to tono / con / oboe y fagot obligados (en lugar } \\
\text { de fagot sele puso viola p q no hay q. lo toque) } \\
\text { No.5, Son } 7 p p \text { 12, Fa }\end{array}$ & A0756 & $29 / 27$ \\
\hline 12. Manuel DELGADO & 6 & $\begin{array}{l}\text { Juego de versos / de } 4^{\circ} \text { tono / con Orquesta / PMD } \\
\text { No. } 12, \text { Son } 5 \mathrm{pp}, \text { Re menor }\end{array}$ & A0757 & $14 / 13$ \\
\hline 13. Manuel DELGADO & 5 & Versos de $6^{\circ}$ tono $2^{\circ} M . D$ & $\mathrm{~A} 0758$ & $11 / 11$ \\
\hline 14. Manuel DELGADO & 5 & $\begin{array}{l}\text { Juego } 2^{\circ} \text { de versos pa. 6to To. MD } \\
\text { No.9, Son } 9 p p . F a\end{array}$ & $\mathrm{~A} 0759.02^{2}$ & $19 / 19$ \\
\hline 15. Manuel DELGADO & 6 & Versos de $6^{\circ}$ tono por Man. Delg. & $\mathrm{A} 0760$ & $36 / 35$ \\
\hline 16. Manuel DELGADO & 5 & $\begin{array}{l}\text { No. } 6 \text { Versos de } 5^{\circ} \text { tono No. } 15 \\
\text { Re, Son } 12 p p\end{array}$ & A0761 & $30 / 30$ \\
\hline 17. Manuel DELGADO & 6 & No. 4 Versos de quinto tono No. 18 & A0762 & $67 / 65$ \\
\hline 18. Manuel DELGADO & 6 & Versos por M.D. & A0763 & $2 / 2$ \\
\hline 19. Manuel DELGADO & 5 & $\begin{array}{l}\text { Versos de } 5^{\circ} \text { (re) orquesta chica / Por D. Manl. Delgado } \\
\text { Copiante J.P. Carrillo Nbre } 3 \text { de } 1877\end{array}$ & A0764 & $22 / 22$ \\
\hline 20. Manuel DELGADO & 6 & $\begin{array}{l}\text { Versos de 1mer tono. Por D. Manuel Delgado } \\
\text { Propiedad de J.Pilar Carrillo }\end{array}$ & $\mathrm{A} 0765^{3}$ & $37 / 35$ \\
\hline 21. José Mariano MORA & 6 & $\begin{array}{l}\text { Catalogo N. } 11 \text { / Baxo Pral. / Versos de } 5^{\circ} \text { tono / Por D. Je. Mora / Violines } \\
\text { 4: Bajos 2: Clarinettes 2: Trompas 2 y / Timbales. / De (no se entiende) } 1840 .\end{array}$ & A0903 & $38 / 34$ \\
\hline
\end{tabular}

Tabla 1. Información relativa a los versos instrumentales de José Manuel Delgado, José Mariano Mora y José Manuel Aldana en la Catedral de México.

2 Versión del A0752.

3 Versión posterior del A0748. 
En aquella época, la de los compositores cuya obra y contexto abordaré, el arte en Occidente pasó de ser algo que se hacía para un fin (la liturgia, el entretenimiento, etc.) a ser algo en sí mismo, es decir, una "obra musical" [GOEHR (2007)]. Por lo mismo, la categoría de músico sufrió un giro radical en donde la imagen y los sentimientos de éste, al igual que sus creaciones, empezaban adquirir un papel cada vez más intercambiable y protagónico. No obstante, uno de los puntos más importantes para el muy joven debate en torno a la música transicional entre la Nueva España y el México Independiente es que las reformas borbónicas, provenientes del absolutismo ilustrado, nunca fueron formuladas, ni en Madrid ni mucho menos en los virreinatos, en términos de una "revolución en el gobierno" frente a antiguos regímenes, por lo que no presentan un carácter innovador ${ }^{4}$. Por lo mismo y al igual que en España, los dos ámbitos musicales predominantes en la segunda mitad del siglo XVIII siguieron siendo la Iglesia y el teatro. Además, en lo que se refiere a la producción local escrita, la Iglesia siguió teniendo el liderazgo en términos cuantitativos, al menos hasta la primera mitad del siglo XIX.

Ciertamente, tanto en los manuscritos de los juegos de versos como en los mismos instrumentistas de esta época transicional observaremos cambios no muy definidos, que se deben, en gran parte, a los giros y desplazamientos conceptuales mencionados y reflejados en creciente circulación de impresos provenientes de Europa ${ }^{5}$. Por ejemplo, se observa la falta de un estilo definido, como el estilo galante en las obras de Jerusalem [RINCÓN (2016)], o la adopción de nueva terminología en los tempi, entre otros aspectos. Así, cuando hay mayor cantidad de información musical que se distribuye más democráticamente entre grupos que conforman una población, los signos se conectan de manera más azarosa. Por lo mismo, en vez de crear una adecuada periodización sobre un "clasicismo musical" o hablar de un "estilo clásico” en la Nueva España y el México Independiente, como se ha intentado hacer anteriormente, ${ }^{6}$ la pregunta que trataré de

4 LEMPÉRIÈRE (2013): 163-167.

5 En 1801, el inventario de la librería de José Fernández Jáuregui de la Ciudad de México ("Abaluo de los papeles de música pertenecientes del Albacenazgo del difunto P. Dn. José Fernández Jaúregui, año de 1801”, en "Testamentaria de José Fernández Jaúregui...", Archivo General de la Nación (MEX-Magn), Tierras, vo. 1334, fol. 522) contaba con música instrumental de compositores vivos y activos en países tales como Alemania (Christian Cannabich *1731; †1798; Franz Anton Hoffmeister *1754; $\dagger 1812$; Johannes Simon Mayr $* 1763$; $\dagger 1845$; Johann Christian Vogell *1756; $\dagger 1788$; etc.), Francia (Ettienne Bernard Barriere *1748; $\dagger 1818$; Jean Baptiste Davaux *1737; $\dagger 1822$; Rodolphe Krutzer $* 1766 ; \dagger 1831$ ), Austria (Franz Joseph Haydn *1732; †1809; Wolfgang Amadeus Mozart *1756; †1791), Bohemia (Leopold Koželuch *1747; †1818; Adalbert Gyrowetz *1763; †1850; Ludwig Wenzel Lachnith *1746; †1820; Jan Ladislav Dussek $* 1760 ; \dagger 1812$; etc), Italia (Muzio Clementi $* 1752 ; \dagger 1832$; Domenico Cimarosa *1749; $\dagger 1801$; Niccolo Piccini *1728; $\dagger 1800$; etc), entre otros. Curiosamente en esta extensa lista no existe ningún compositor de nacionalidad española, a excepción de Luggi Boccherini, de origen italiano, y tres compositores novohispanos (Ignacio Jerusalem, José María Aldana y Francisco Delgado): MIRANDA (1997): 49-50.

6 En uno de los artículos pioneros al respecto [MIRANDA (1997): 39-50], el musicólogo mexicano Ricardo Miranda establece responder aquí es: ¿cómo influyeron estos horizontes conceptuales de expansión global en un contexto litúrgico novohispano de finales del siglo XVIII, y cuáles fueron los procesos sincréticos que se dieron en la producción local (específicamente en los versos orquestales de estos tres compositores) durante la transición a lo que llamamos el México Independiente?

El caso de José Manuel Delgado resulta especialmente interesante pues tanto el hecho de que sus juegos de versos sean la parte más cuantitativa del corpus dentro del archivo (MEX$M c)^{7}$, como el hecho de que éstos sean los manuscritos más desgastados, copiados y que tienen más anotaciones superpuestas -y muchas veces contradictorias-sugieren que pudieron ser los más interpretados dentro del recinto, por lo que resulta difícil establecer una cronología.

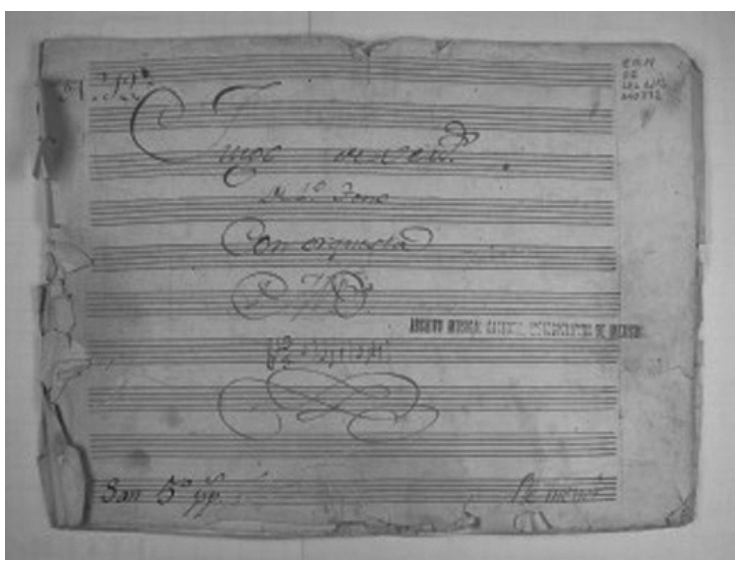

Fig. 1. Portada del juego de versos A0757 de Manuel Delgado $(\boldsymbol{M E X}-M c)$.

José Manuel Delgado nació en Valladolid y en un principio su formación musical estuvo fuera del ámbito eclesiástico:

[...] digo que por cuanto haberme ejercitado en aprender música desde mis tiernos años, con algún trabajo, y esmero, y de esto haber logrado algún aprovechamiento, dispuse con el beneplácito de mis padres, venir a esta Santa Iglesia Catedral, a solicitar una plaza de música. Pues para esto, pongo patente a los

la fecha de inicio para dicho periodo musical como 1770, tomando en cuenta la significativa muerte de Ignacio Jerusalem y la llegada al archivo del Colegio de las Rosas de la obertura de Antonio Sarrier, obra "cuya estructura sonata anuncia un novedoso y fundamental concepto de la forma musical sine qua non del clasicismo". [MIRANDA (1997): 43]. Asímismo, establece la muerte de Mariano Elízaga en 1842 como el final de esta clasificación historiográfica.

$7 \mathrm{El}$ orden cuantitativo del corpus de juegos sobrevivientes es el siguiente: M. Delgado: 17 juegos; I. Jerusalem: 9; F. Delgado: 4; M. Aldana: 3; C. P. Vázquez: 2; B. Asioli: 1; J. Beristain: 1; L. Beristain: 1; J. M. Bustamante: 1; C. Echevarría: 1; J. M. Mora: 1; F. Osorio: 1; I. Solares: 1 ; N. Sort de Sáenz: 1 ; y A. Valle: 1. 
ojos de Vuestra Señoría las dos habilidades que gozo, que son, tocar violín, y voz para cantar, generalmente en música suelta, $\mathrm{y}$ tocar tan bien sin reservar obra alguna de las que se practican en el culto divino, excepto la música de facistol por no haberla visto en donde aprendí pero, no obstante, me obligo dentro de muy corto tiempo a hacerme cargo de ella y ejecutarla $[\ldots]^{8}$.

La educación musical en ésta época se encuentra cada vez más emancipada y relajada respecto a la Iglesia como institución formativa, por lo que los usos y costumbres litúrgicas también. Músicos como M. Delgado aprendían posteriormente a leer tanto la notación del canto llano como la notación mensural de la polifonía, más que nada como una forma de acceder a la plantilla de alguna de las catedrales o iglesias menores, siendo éstas el mejor -y más estable- trabajo remunerado al que podía acceder cualquier músico.

Delgado accedió a una plaza en la Catedral de Valladolid como violinista y fue nombrado tanto primer violín como primera flauta con la también "obligación de enseñar a los niños". En 1778 , se trasladó a la Ciudad de México para trabajar al servicio del Conde de San Matheo. Más tarde, con la intención de establecerse definitivamente en la ciudad con un "destino honroso" 10 , M. Delgado fue aceptado en la Catedral de México "unánimemente por su notoria habilidad" en la plaza de $2^{\circ}$ violín, con un salario de 225 pesos anuales ${ }^{11}$. Seis años después de ser aceptado como músico de la catedral, encontramos también un documento en las Actas de Cabildo que llama especialmente la atención al develar tanto las actividades de músicos como $\mathrm{M}$. Delgado y M. Aldana en el Coliseo y en el Palacio Real, como los problemas que estas mismas les llegaron a causar:

[...] el Señor Dean dijo que su Excelencia Señor Virrey le había encargado hiciere presente a este vuestro Cabildo que estando determinado por su Excelencia y otros Sujetos principales de esta Ciudad formar una sociedad, cuyo objeto fuese purgar todos los vicios y desórdenes del teatro, reduciendo las diversiones a unas óperas, las que se habrían de representar en el Real Palacio, para lo que ya está formado el Teatro, y necesitándose para esto músicos de habilidad y destreza, habiendo en esta Santa Iglesia en el servicio de su Capilla tres Individuos sobresalientes en la habilidad del violín, los cuales son Don Gregorio Panseco, Don Manuel Delgado y Don José Aldana, atendiendo a que el primero tiene el genio ríspido: lo que puede traer algunos litigios, que los otros dos siendo de el agrado de este V. Cabildo, y sin que en ello se perjudicase a la Iglesia se señalasen para aquel Teatro sin prejuicio de sus plazas en la Capilla. Lo que habiendo oído, dijeron algunos señores que este era un caso sin ejemplar, e inaudito, respecto

$8 \boldsymbol{M E X}$ - $M c$, leg. 3.1-100, f. 193r, [hacia el 20.06.1761]. Información tomada de ROUBINA (2009): 18-19.

$9 \boldsymbol{M E X}-\mathbf{M c}$, Actas de Cabildo f. 73v, [24.10.1772]. Información tomada de ROUBINA (2009): 26-27.

$10 \mathrm{Ibid}$.

$11 \boldsymbol{M E X}$-Mc, Actas de Cabildo, libro 54, f. 239r, 04.07.1780. a parecer repugnante el servicio de la Iglesia con el del Teatro: pero que lo mas era, que las reglas, u ordenanzas de los músicos disponen, no puedan tener otra asistencia u ocupación, estando en esta Capilla, si no fuere con especial licencia del Ilustrísimo Señor Arzobispo y del Venerable Cabildo. En vista de lo cual a pluralidad de votos se acordó, que el señor Dean diga al Excelentísimo Señor Virrey, que condescendiendo el Señor Arzobispo en que estos dos Individuos de la Capilla asistan en las expresadas óperas, también condesciende este Cabildo... ${ }^{12}$.

Cinco años después, el 22.03.1790, el juez del coliseo, don Cosme de Mier y Trespalacios, se dirigió al nuevo virrey para que intercediera con las autoridades eclesiásticas y, de esta forma, los músicos de la Catedral pudieran asistir de nuevo y sin restricciones a la "Horquesta del Teatro". Después de todo, la Iglesia seguía siendo el primer vínculo político de la monarquía católica, y la mediación de ésta era a su vez una necesidad:

En un teatro como el de esta Capital donde por una infinidad de efectos inconfundibles no es fácil establecer la ilustración que han adquirido los de Europa, suele ser la música la que llama el concurso de las personas de inteligencia y gusto cuando se compone de una orquesta de los mejores instrumentos y habilidades. La tiene esta Santa Iglesia: las horas son distintas de las del Teatro y no hay incompatibilidad en la asistencia de algunos que a imitación de lo hecho en el año de 1785 que interpuso su autoridad... ${ }^{13}$.
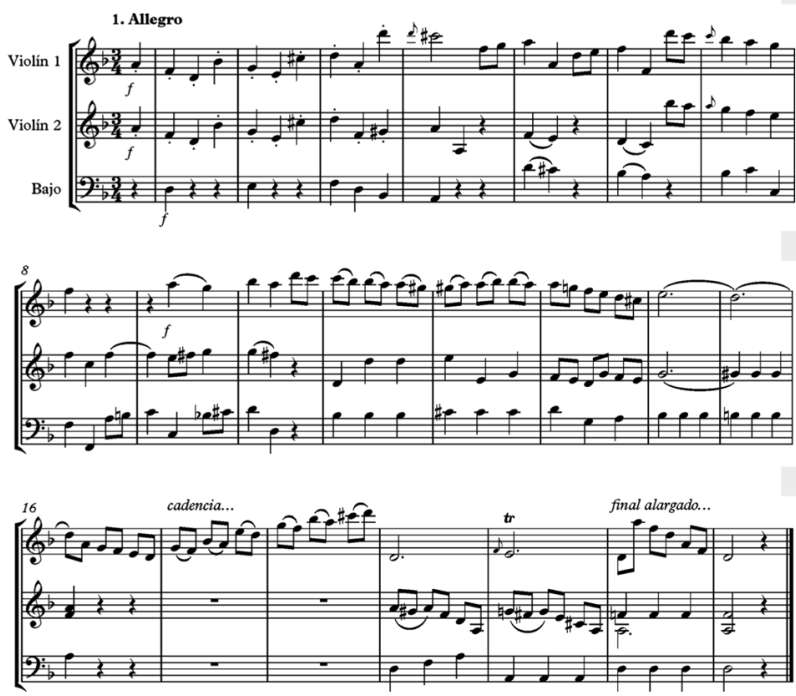

Ejemplo 1. Primer verso (Allegro) del Juego A0757 de M. Delgado.

$12 \boldsymbol{M E X}-\mathbf{M c}$, Actas de Cabildo, libro 56, folio $11 \mathrm{r}$ y $11 \mathrm{v}$, 14.03.1786.

$13 \boldsymbol{E}-M n$, FR MS1410, "Asuntos de teatros", t. 32, ff. 289r-v, 22.03.1790. Información tomada de ROUBINA (2009): 41-42. 
Más que un estilo muy definido, como en el caso de Ignacio Jerusalem y el estilo galante, los versos de Delgado y sus contemporáneos contienen una escritura que yo he llamado "ilustrada", con elementos anacrónicos y misceláneos con mucha influencia del estilo italianizado pero también con algunos rasgos significativos de la escuela vienesa, e inclusive, elementos del barroco alemán. El llamado barroco tardío está aquí muy presente, con cromatismos, texturas homogéneas por terceras, modulaciones, y algunas veces ritmos contrastantes. En el siguiente ejemplo, sin embargo, existen ritmos más homogéneos entre el bajo y los violines, un poco más de interacción e imitación entre las tres voces después de la corta exposición del tema, y un pequeño solo o cadencia escrita, que dilata a su vez la cadencia final:

En otro juego de versos, también encontramos un exótico "clarinete recitado" (con un Do menor armónico) ${ }^{14}$ con acompañamiento de violín en el cuarto verso del juego. Este tipo de recurso "operístico" en que los instrumentos asemejan recitativos vocales es común en la música instrumental de las cortes europeas en donde el estilo italianizado se habían apropiado de la música instrumental del barroco tardío ${ }^{15}$ :

Continuando con la influencia de la ópera en la música instrumental, en muchos de los primeros versos de los juegos de estos tres compositores, tenemos movimientos que empiezan con estructuras rítmicas homogéneas, comunes en las oberturas operísticas, para después desarrollar o introducir otros temas que van emancipando las diversas voces, ya sea con diminutos solos o en secciones instrumentales (cuerdas, instrumentos de viento madera o metal, y bajos). Tal es el caso de los ejemplos siguientes: el juego A0756, el A0755, el A0756, y el A0765 (también A0748) de M. Delgado.

Gran parte de los juegos de versos a partir de M. Delgado tienen un discurso musical un poco más largo y definido en cuanto a duración y forma, es decir; versos que cuentan con introducción, tema, solos o frases cada vez más independientes, recapitulación y/o resolución; y en cuya "trama" la retórica musical tan practicada en el barroco, y exaltada en el barroco tardío, tiene un papel protagónico. Los versos A0756, y A0765 o A0748 respectivamente forman parte de los juegos que quizá llaman más la atención en este sentido.

Esto último me lleva a hablar de las condiciones en las que varios de los juegos probablemente fueron escritos: En el mismo año de 1802, la muerte de Juan Gregorio Panseco dejó vacante la plaza de primer violín de la capilla de la Catedral de México, por lo que M. Delgado aprovechó la oportunidad para quedarse con ella, y le escribió una carta al deán argumentando que:

14 Este tipo de sonoridad, con influencia andaluza, la encontramos también en otras composiciones de José M. Aldana.

15 Uno de los ejemplos más tempranos de estos recitativos de instrumentos lo encontramos en el movimiento lento del concierto para violín de Antonio Vivaldi (RV 208). Otros ejemplos más comunes y tardíos los encontramos con compositores tales como Carl Philipp Emanuel Bach (sonatas prusianas), Federico el Grande (sonatas como la Sonata, per il Flauto Traverso Solo e Basso en Do menor, "pour Potsdam" No. 190) y Joseph Haydn (Sinfonía No. 7, Cuartetos Op. 9 y 17), entre otros.
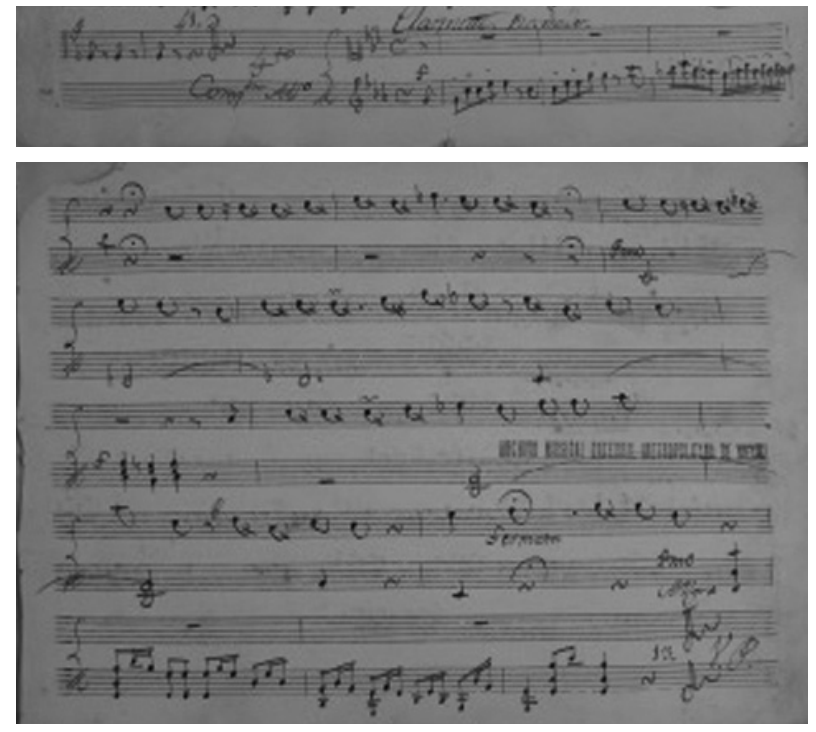

Fig. 2. "clarinete recitado" y violín 1 del cuarto verso del Juego A0760 (MEX-Mc).

[...] veinticinco años ha que estoy en el coro de esta Santa Iglesia con sólo el sueldo de cuatrocientos pesos. Y aunque mi plaza en que su generosidad me admitió sólo fue de violín, he tenido en todo este tiempo el cuidado de asistir al primer violín, gobernando la orquesta, y llevando la música más exquisita [...] En todas las veces que ha faltado con precisión de obligados, viola, flauta, violoncello, y aún el órgano; no sufriendo falte a la Iglesia la decencia posible: he tomado dichos instrumentos, para que no se haga falta alguna... ${ }^{16}$.

Sabemos por documentos de la Catedral de Morelia y de la Ciudad de México, que además de tocar varios instrumentos, como era costumbre de la época, M. Delgado contribuyó con nuevas composiciones, como juegos de versos, "de modo que no se puedan oír en parte alguna más que en el coro de mi Santa Iglesia"17. Además, el Diario de México menciona unos años después que:

El día de la Ascensión se celebró la hora nona en la santa iglesia catedral, con la solemnidad acostumbrada, tocándose por la orquesta, en los intermedios de los versículos del segundo salmo, una excelente composición de don Manuel Delgado, natural de Valladolid. Es notoria la habilidad y destreza de este profesor en el violín y otros instrumentos $[\ldots]^{18}$.

$16 \boldsymbol{M E X}$ - $M c$, Correspondencia, caja 24, exp. 8 s.f., marzo de 1802. En la disputa de dicha plaza que ya tenía sus antecedentes, M. Aldana fue el principal rival de Delgado. Sin embargo, el 06. 04.1802, M. Delgado fue "nombrado por mayor número de votos en la plaza de primer violín".

$17 \mathrm{Ibid}$. Esta forma de agradecer o buscar favores del cabildo a cambio de nueva música era una práctica muy común de la época.

18 Diario de México, 14.05.1807. Recordemos que el Diario de México había aparecido apenas dos años antes de ésta publicación, pre- 
Por tanto, la infiltración del movimiento de la Ilustración en las celebraciones no solo se desplaza al lenguaje musical de las obras catedralicias y conventuales sino también a la misma concepción social de la música dentro de la Iglesia, la cual empieza a ser comentada y resaltada como objeto digno de historizar y comentar en publicaciones de gacetas y periódicos como El Diario Literario de México (a partir de 1778) o la Gazeta de México (a partir de 1784). Compositores como Delgado empiezan a adquirir la noción de escribir no sólo para una celebración religiosa, sino además para un público atento a la música como objeto fuera del ritual, es decir; la música reseñada en el comentario musical impreso, y con esto, el reconocimiento per se de la obra y su autor. Cabe destacar también que tanto M. Delgado como M. Aldana participaron en los muy probablemente primeros recitales públicos en México, llevados a cabo entre 1807 y 1808 en el Palacio de Minería ${ }^{19}$, e impartieron cátedras a miembros de las familias ricas de la capital del país. Así, una de las razones que podría explicar que algunos de los juegos de versos tengan un discurso más estructurado que otros, que hayan sido copiados, que empiecen de forma más solemne con movimientos lentos (como el A0748, A0752, A0753 y A0762) o que contengan una instrumentación más nutrida (como el A0753, el A0765 -también A0748-, o el A0762, éste último con "órgano obligado"), puede ser que dichas tipologías fueron compuestas para celebraciones específicas y de especial importancia, como la del día de la Ascensión mencionada en el Diario de México.

Respecto a la instrumentación de los versos, como podemos ver en la indicación del A0756, ésta era en parte adaptable a los instrumentos con los que contó la capilla a lo largo de los años en que dichas tipologías fueron interpretadas, como es el caso de los clarinetes en vez de los oboes en los versos de M. Delgado y M. Aldana. O también el juego A0762, único de M. Delgado que tiene flautas, viola y órgano obligado, y sin embargo, el fagot dobla la parte de la viola, por lo que es muy probable que esta última se añadiera en circunstancias similares a las del A0756.

Otros elementos importantes que encontramos por primera vez a partir de M. Delgado son el uso de tonalidades menores en los versos, la nomenclatura "orquesta", "grande orquesta", así como más linealidad en el bajo y finales prolongados a base de la repetición de una nota o acorde. Ciertamente, a pesar de los elementos dominantes del barroco tardío, esto último nos remite al llamado clasicismo musical, estilo que prolongó quizá como ninguno la cadencia final en el lenguaje tonal.

cedido en 1768 por la publicación semanal de El Diario Literario de México, primer periódico de corte ilustrado que aparece en la Nueva España.

19 Ibid, 24.10.1807.

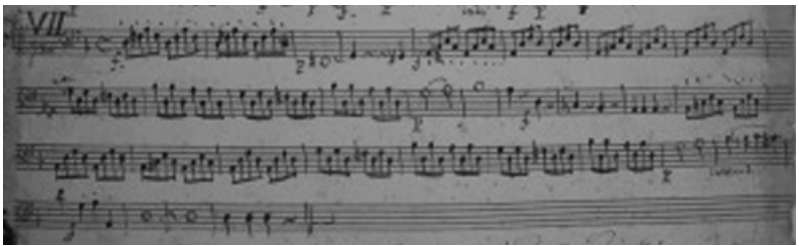

Fig. 3. Parte del bajo del séptimo verso del Juego de versos A0752 (MEX-Mc)

Los tres juegos de versos de José Manuel Aldana que se conservan en la Catedral de México comparten muchas características misceláneas con los versos de M. Delgado y también presentan algunas diferencias. Por ejemplo, tenemos principios en unísono para después hacer una exposición por temas intercalados, así como respuestas por medio de las diferentes voces. También encontramos bajos de Alberti, esta vez como acompañamiento de la mano izquierda en los órganos obligados, así como finales extendidos, es decir, finales en donde la última nota se repite para prolongar el final de forma dramática. En el juego A0686 hay por primera vez una partitura con la parte de los dos órganos obligados, el violín 1 y el bajo. Este tipo de manuscritos, con todas o muchas de las distintas partes juntas, servían como una guía para el maestro de capilla, y los empezamos a encontrar en la Catedral de México a partir de la presencia de Antonio de Juanas como maestro de capilla.

Aunque la documentación histórica sobre la vida de Aldana es bastante esporádica ${ }^{20}$, este músico fue uno de los principales protagonistas de las publicaciones y debates musicales del Diario de México a principios del siglo XIX. Así, cabe mencionar aquella sugerencia de un lector respecto a que Aldana cambiara su nombre por el de "Aldani" o "mister Eldem", para contar así con más reconocimiento ${ }^{21}$. O la controversia surgida a raíz de un artículo del mismo diario en 1806 que comparaba a Aldana con Ignaz Pleyel $(* 1757 ; \nmid 1831)$, y después con Antonio Lolli (*1725c; $\uparrow 1802)$, la cual fue refutada por un lector anónimo que argumentaba que, a pesar de ser buen violinista, como compositor, Aldana se limitaba a escribir "contradanzas, minuetes, boleras, polcas y otros juguetes de esta naturaleza"22. No obstante, aunque tanto los músicos como la audiencia de la época se esforzaban por "establecer la ilustración que han adquirido los de Europa"23, la vida social novohispana, con su realidad colonial de aculturación y descontextualización, adoptó y transformó el sentido de aquellos "géneros indignos"24, como les llamaban en ciudades como Viena, considerándolos en gran parte "ilustrados" por el sólo hecho de provenir de Europa.

20 Ver la Biografía revisada en: HERNÁNDEZ MONTERRUBIO (2001): 9-30.

21 Diario de México, 13.10.1805.

22 Diario de México, 17.12.1806.

$23 \boldsymbol{E}-\mathbf{M n}$, FR MS1410, "Asuntos de teatros", t. 32, ff. 289r-v, 22.03.1790. Información tomada de ROUBINA (2009): 41-42.

24 WEBER (2008): 96. 


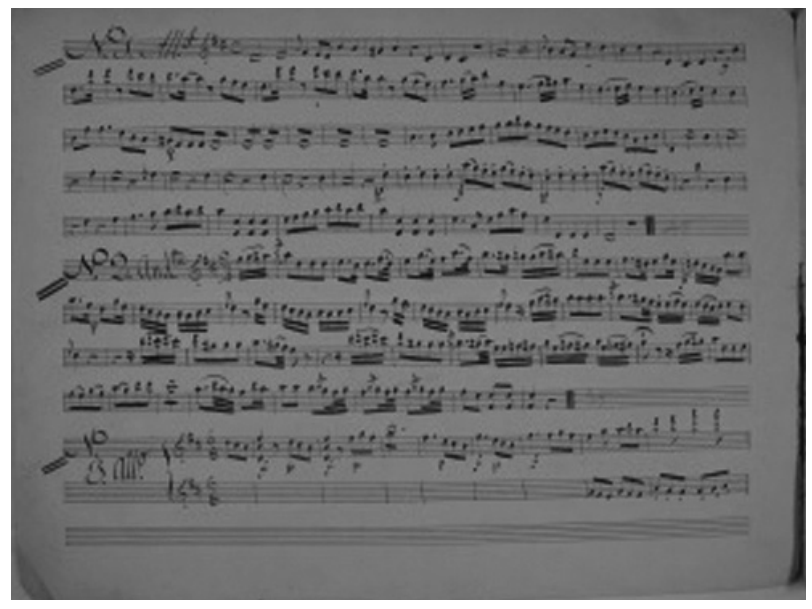

Fig. 4. Parte del violín 1, del juego de versos A0685 de J. M. Aldana $(\boldsymbol{M E} \boldsymbol{X}-\boldsymbol{M c})$.

A diferencia de M. Delgado y M. Aldana, José Mariano Mora fue organista, violista de la Catedral y director de la escoleta de música de esta institución. También trabajó en la Basílica de Guadalupe como violista, en cuyo archivo se encuentran, entre otras muchas composiciones litúrgicas, ocho juegos más de versos "a toda Horquesta"25. Lo más llamativo del juego de versos de M. Mora son aquellas características que nos recuerdan la música organística del barroco alemán, estilo que para la Europa de esa época debió de haber parecido tan solo una resonancia del pasado de la antigua música eclesiástica, o un "espectro del pasado", como diría Aby Warburg.

Por ejemplo, el siguiente fragmento transcrito es una pequeña fuga para instrumentos que nos recuerda el oficio de $\mathrm{M}$. Mora como organista y músico de Iglesia. A diferencia de otros contemporáneos como Delgado y Aldana, no se conserva ni se tiene registro alguno de sus obras profanas:

En su libro "Introducción al Análisis de Textos" [MIER (1990)], el antropólogo mexicano Raymundo Mier analiza las transformaciones ideológicas a lo largo de la historia que dieron fundamento al análisis de textos ${ }^{26}$, y se pregunta: “¿dónde empieza y donde termina el texto?", para luego añadir que "hablar

$25 \boldsymbol{M E X}-\mathbf{M r c}$, Sig. 1035. En este juego de versos encontramos como introducción el siguiente poema escrito por el mismo Mora: Pequeña la obra: el autor pequeño; / Mas la dedico con afecto sumo, / Bien satisfecho de que es grato el humo, / Del holocausto puro en desempeño. / No hablar del divino sacro empeño / Que de la Vid feliz trasforma el zumo: / Ni una imagen hallar jamás presumo / A fuerza de pulir el rudo leño / En simulacro miro convertido / El Ayate de un pobre Mexicano; / ¡Así el Cielo mi Patria ha distinguido! / Haydem, Pleier Mozar::: dexad q. Ufano / A Guadalupe vuele y que vendido / Borroncillo presente de mi mano.

26 Aunque R. Mier se refiere al análisis de textos en general, la similitudes con la notación musical no dejan de encontrarse "entre líneas"; después de todo, las diversas escrituras son fenómenos análogos al lenguaje. de texto es no sólo hablar de una superficie de signos, sino de la lectura que lo hace posible. [...] Hablar de lectura es hacer referencia también a un momento que constituye esencialmente el acto de hablar, de enunciar, de escribir [de ejecutar y escuchar la música]. La escritura es sólo un testimonio, no pocas veces inclemente, de la lectura" 27 .
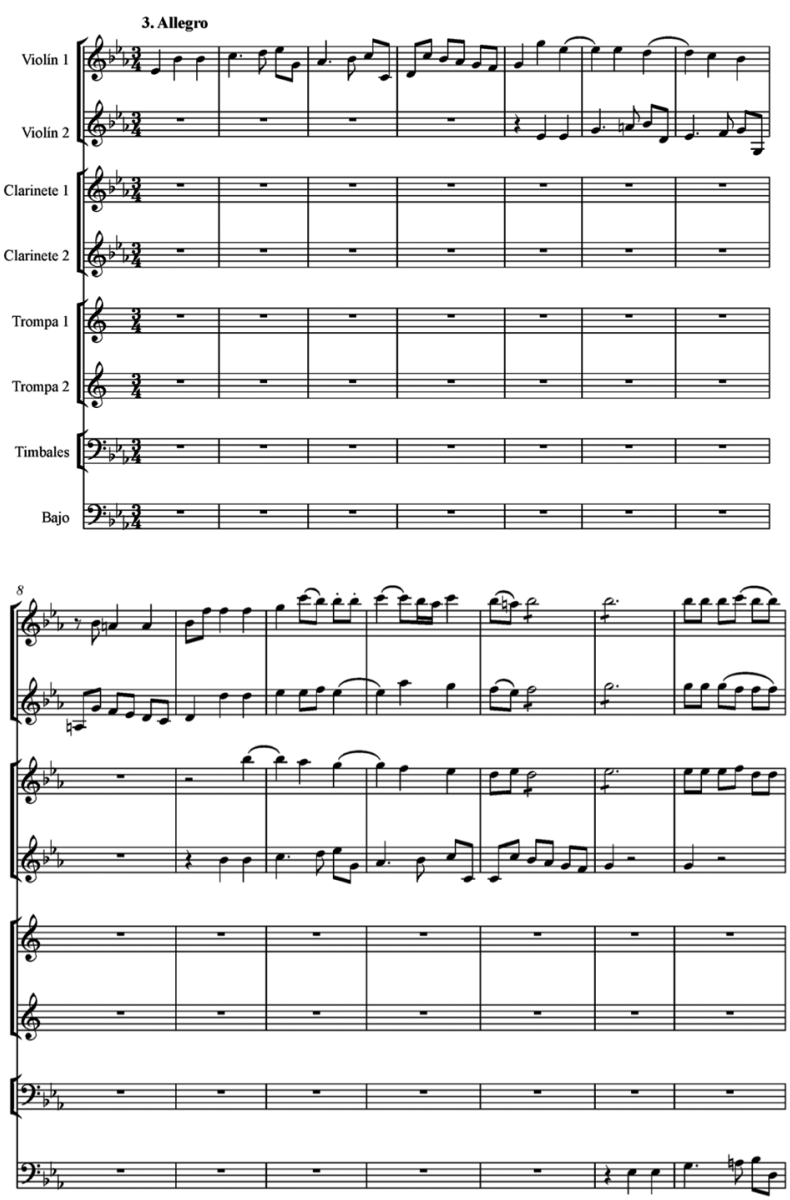

Ejemplo 2. Principio del Allegro (verso 3) en fuga, del juego A0903 de M. Mora.

$\mathrm{Al}$ alternarse con el canto llano y formar parte de la práctica espacial, temporal y conceptual de la liturgia, los versos instrumentales y orquestales son ciertamente testimonios inclementes de la lectura. Su adaptación a las celebraciones condicionaba directamente no sólo el inicio y terminación de cada verso, sino también los tempi utilizados en la práctica que tenían que ensamblarse al canto, a la intención y solemnidad de los textos litúrgicos, al tono, y a la duración de la música figurada. Estos aspectos llegan

27 MIER (1990): 133. 
incluso a contradecir la terminología usada en los manuscritos, por lo que es importante mencionar que la alternancia con el canto llano, además, saca a la luz un tema aún no tratado y reflexionado en la historiografía de la música catedralicia en México: la adopción progresiva de la tonalidad bimodal -modos mayor y menor-, así como su alternancia y adaptación al sistema modal.

Es importante aclarar que cuando hablamos de tonos de los salmos y de modos, no estamos hablando de lo mismo: con el paso del tiempo, los tonos salmódicos y los modos terminaron por ser entidades musicales diferentes; un modo es una categoría abstracta, mientras que un "tono salmódico" es una entidad musical concreta. Al respecto, el musicólogo norteamericano Harold Powers, en su artículo From Psalmody to Tonality ${ }^{28}$, marca una diferenciación muy acertada cuando dice que más que incorporar el tono salmódico, los compositores lo representaban en la obra ${ }^{29}$. Esto último define muy bien el caso de los versos instrumentales en la Catedral de México en donde no se reconocen literalmente las fórmulas salmódicas sino su representación, lo que se demuestra con aspectos tales como la duración, el número de versos, las armaduras, las notas iniciales y las finales.

Los tonos de canto de órgano en donde cada vez más se representaban las fórmulas salmódicas, en vez de citarse literalmente, son además un ejemplo de la introducción paulatina de la tonalidad bimodal dentro de la Iglesia. Así, en 1778, el músico madrileño Francisco Santamaría y Fuentes mencionaba que:

[...] Estas dos consonancias las llaman algunos modo mayor a la primera y modo menor a la segunda [...], pero en nuestra España, como lo más que se escribe es para la iglesia, y no para el teatro, se usan los ocho modos, o tonos, los que tienen en sus diapasones algunas diferencias que les distinguen de los dos modos dichos ${ }^{30}$.

Esto último, como podemos observar, fue causa de que se utilizara la palabra "tono" como sinónimo de "modo", lo que desde entonces y hasta la fecha, ha conllevado muchas confusiones.

\begin{tabular}{|l|l|l|l|l|l|l|}
\hline Compositor & No. de V. & Sig. & Final & Armadura & Tono indicado & Posible correlación de los modos: \\
\hline 1. J. M. Aldana & 6 & $\mathrm{~A} 0685$ & $\mathrm{Re}$ & $2 \#$ & $5^{\circ}$ & $5^{\circ}$ transportado: Ffaut \\
\hline 2. J. M. Aldana & 6 & $\mathrm{~A} 0686$ & $\mathrm{Re}$ & $2 \#$ & & $5^{\circ}$ transportado: Ffaut \\
\hline 3. J. M. Aldana & 6 & $\mathrm{~A} 0687$ & $\mathrm{Re}$ & $1 \mathrm{~b}$ & $1^{\circ}$ & $1^{\circ}:$ Dlasolre \\
\hline 4. M. Delgado & 6 & $\mathrm{~A} 0748$ & $\mathrm{Do}$ & $3 \mathrm{~b}$ & $1^{\circ}$ & $1^{\circ}$ transportado: Dlasolre \\
\hline 5. M. Delgado & 7 & $\mathrm{~A} 0754$ & $\mathrm{Re}$ & $1 \mathrm{~b}$ & $1^{\circ}$ & $1^{\circ}:$ Dlasolre \\
\hline 6. M. Delgado & 5 & $\mathrm{~A} 0750$ & $\mathrm{Sol}$ & $1 \#$ & $8^{\circ}$ & $8^{\circ}:$ Gsolreut \\
\hline 7. M. Delgado & 6 & $\mathrm{~A} 0751$ & $\mathrm{Mi}$ & $1 \#$ & $2^{\circ}$ & $2^{\circ}$ transportado: Dlasolre \\
\hline 8. M. Delgado & 7 & $\mathrm{~A} 0752$ & $\mathrm{Re}$ & $1 \mathrm{~b}$ & $1^{\circ}$ & $1^{\circ}:$ Dlasolre \\
\hline 9. M. Delgado & 5 & $\mathrm{~A} 0753$ & $\mathrm{Re}$ & $1 \mathrm{~b}$ & $1^{\circ}$ & $1^{\circ}:$ Dlasolre \\
\hline 10. M. Delgado & 6 & $\mathrm{~A} 0755$ & $\mathrm{Mi}$ & $4 \#$ & $6^{\circ}$ & $6^{\circ}:$ Ffaut \\
\hline 11. M. Delgado & 5 & $\mathrm{~A} 0756$ & $\mathrm{Fa}$ & $1 \mathrm{~b}$ & $6^{\circ}$ & $6^{\circ}:$ Ffaut \\
\hline 12. M. Delgado & 6 & $\mathrm{~A} 0757$ & $\mathrm{Re}$ & $1 \mathrm{~b}$ & $1^{\circ}$ & $1^{\circ}:$ Dlasolre \\
\hline 13. M. Delgado & 5 & $\mathrm{~A} 0758$ & $\mathrm{Fa}$ & $1 \mathrm{~b}$ & $6^{\circ}$ & $6^{\circ}:$ Ffaut \\
\hline 14. M. Delgado & 5 & $\mathrm{~A} 0759$ & $\mathrm{Fa}$ & $1 \mathrm{~b}$ & $6^{\circ}$ & $6^{\circ}:$ Ffaut \\
\hline 15. M. Delgado & 6 & $\mathrm{~A} 0760$ & $\mathrm{Mi} \mathrm{b}$ & $3 \mathrm{~b}$ & $6^{\circ}$ & $6^{\circ}$ transportado: Ffaut \\
\hline 16. M. Delgado & 5 & $\mathrm{~A} 0761$ & $\mathrm{Re}$ & $2 \#$ & $5^{\circ}$ & $5^{\circ}$ transportado: Ffaut \\
\hline 17. M. Delgado & 6 & $\mathrm{~A} 0762$ & $\mathrm{Re}$ & $2 \#$ & $5^{\circ}$ & $5^{\circ}$ transportado: Ffaut \\
\hline 18. M. Delgado & 6 & $\mathrm{~A} 0763$ & & & & \\
\hline 19. M. Delgado & 5 & $\mathrm{~A} 0764$ & $\mathrm{Re}$ & $2 \#$ & $5^{\circ}$ & $5^{\circ}$ transportado: Ffaut \\
\hline 20. M. Delgado & 6 & $\mathrm{~A} 0765$ & $\mathrm{Do}$ & $2 \mathrm{~b}$ & $1^{\circ}$ & $1^{\circ}$ transportado: Dlasolre \\
\hline 21. J. M. Mora & 6 & $\mathrm{~A} 0903$ & $\mathrm{Mi} \mathrm{b}$ & $3 \mathrm{~b}$ & $5^{\circ}$ & $5^{\circ}$ transportado: Ffaut \\
\hline
\end{tabular}

Tabla 3. Información de los versos para su uso en alternatim con el canto.

Los tratadistas españoles de los siglos XVIII y XIX exponían y explicaban dicha transición por la que atravesaba la música en el templo, ${ }^{31}$ así como su alternancia con los tonos tradicionales del canto llano. En 1762, Antonio Soler, compositor y organista, quien

28 POWERS (1998): 274-277.

29 POWERS (1998): 289. además había sido discípulo de José de Nebra $(* 1702 ; \nmid 1768)$ y Domenico Scarlatti $(* 1685 ; \uparrow 1757)$, menciona lo siguiente:

30 SANTA MARÍA (1778): 170-171.

31 Entre los tratados españoles de la época que abordan el tema están: TORRES MARTÍNEZ-BRAVO (1702-1736); BONASTRE et alii [Rabassa] (1990); SOLER (1762); NASSARRE (1723-1724); SANTA MARÍA (1778); VARGAS Y GUZMÁN (1776); este último, es de los pocos tratados teóricos que fueron escritos en la Nueva España y que se conservan actualmente en México; etc. 
[...] todo diapasón, o bien es de tercera mayor, o bien de tercera menor; pero si los tonos tuvieran que unirse con los del canto llano, entonces no guardan todos una misma formación de diapasón [...], pues siguiendo la común práctica de España e Italia, no hay más que los dos que dije para toda especie de música suelta ${ }^{32}$.

Como he mencionado, estamos en una época en que los grandes teatros de ópera, y más tarde, los salones e instituciones musicales al servicio del Estado, empezaban a robarle protagonismo la Iglesia, la cual era consciente de los cambios que sufría la tradición musical dentro de sus templos. En 1795, por ejemplo, en la Catedral de México, se le hicieron varias observaciones a Antonio Juanas $(* 1762 c ; \dagger 1816 c)$ por dejar a un lado la enseñanza del contrapunto, lo que indica la predominancia de los nuevos estilos en las mismas composiciones que aportaban los músicos de la capilla para el uso de la liturgia. De esta forma, las modificaciones de las armaduras y el uso de tonos transportados o de tonalidades con muchas alteraciones en la armadura, se fueron ampliando en la música de la liturgia desde el siglo XVIII con la presencia de I. Jerualem hasta el último maestro de capilla.

Debido a su misma alternancia con el canto llano, los versos instrumentales y orquestales mantienen una necesaria coherencia entre tono y modo, utilizando las alteraciones indispensables para adaptación sonora de la capilla musical, como podemos observar en la Tabla 3.

Respecto al uso de la terminología en los tempi de los versos, tanto en los juegos de versos para instrumentos de la Catedral de México, como en los juegos organísticos que he en- contrado en España, el uso paulatino de terminología fijada en los manuscritos aparece en la segunda mitad del siglo XVIII, lo que coincide con el pensamiento ilustrado y la cada vez más común impresión y circulación de dichos manuscritos fuera de la Iglesia. Además, esto último indica que a pesar de que muchas obras contemporáneas no incluyeran terminología de tempi, el uso consensual en la ejecución era muy común como parte de la retórica musical de la época; tal es el caso de los primeros juegos de versos compuestos por Ignacio Jerusalem [RINCÓN (2016)].

En la Catedral de México encontramos una paleta muy grande de tempi a partir de Manuel Delgado. En su libro Classical and Romantic Performing Practice 1750-1900 33 , el musicólogo inglés Clive Brown analiza y recopila detalladamente los sentidos y variaciones de esta proliferación de términos de tempi expuestos en diversos tratados musicales por músicos europeos, muchos de los cuales, a partir de 1816, incluyen indicaciones de metrónomo ${ }^{34}$. Sin embargo, a pesar de que existía un consenso global que los compositores novohispanos y del México Independiente aplicaron a sus obras, es necesario hablar de nuevo de su ejecución en el templo, de la alternancia con el canto llano y con el canto figurado, de la practicidad y de la movilidad de dichas obras, cuyos manuscritos aparentan tener varias inconsistencias. Así, he llegado a la conclusión, por aspectos que expondré a continuación, de que los compositores usaban la terminología más en boga con la que convivían fuera de la Catedral, pero esas pequeñas diferencias conceptuales que podrían establecer que un allegro no fuera igual a un presto, no eran consideradas en la práctica de los versos.

\begin{tabular}{|c|c|c|}
\hline Compositor & Orden de los tiempos & Sig. \\
\hline 1. J. M. Aldana & 1. Allegro $4 / 4 ; 2$. Andante $2 / 4 ; 3$. Allegro $6 / 8 ; 4$. Andante $3 / 8 ; 5$. Allegro $4 / 4 ; 6$. Allegro $6 / 8$ & A0685 \\
\hline 2. J. M. Aldana & 1. Allegro $4 / 4 ; 2$. Andante $4 / 4 ; 3$. Allegro $4 / 4 ; 4$. Andante $6 / 8 ; 5$. Allegretto $3 / 4 ; 6$. Allegro $6 / 8$ & A0686 \\
\hline 3. J. M. Aldana & 1. Allegro $4 / 4 ; 2$. Andantino 3/8; 3. Allegro 4/4; 4. Andante 3/4; 5 . Allegro 6/8; 6 . Andante & A0687 \\
\hline 4. M. Delgado & $\begin{array}{l}\text { 1. Andante brillante } 3 / 4 ; 2 \text {. Allegro } 4 / 4 ; 3 \text {. Andante } 4 / 4 ; 4 \text {. Maestoso } 3 / 4 ; 5 \text {. Andante } 2 / 4 ; 6 \text {. Allegro non } \\
\text { presto } 3 / 4\end{array}$ & A0748 \\
\hline 5. M. Delgado & $\begin{array}{l}\text { 1. Moderato } 3 / 4 ; 2 \text {. Tempo justo } 2 / 4 ; 3 \text {. Tempo justo } 2 / 4 ; 4 \text {. Andante } 3 / 4 ; 5 \text {. Tempo justo } 2 / 4 ; 6 \text {. Allegro } \\
2 / 4 ; 7 \text {. Presto } 4 / 4\end{array}$ & A0754 \\
\hline 6. M. Delgado & 1. Allegro $4 / 4 ; 2$. Allegro $4 / 4 ; 3$. Allegro $4 / 4 ; 4$. Andante $3 / 4 ; 5$. Allegro $3 / 4$ & A0750 \\
\hline 7. M. Delgado & $\begin{array}{l}\text { 1. Allegro con spirito 4/4; } 2 \text {. Allegretto 4/4; } 3 \text {. Andante 3/4; 4. Allegro 4/4; } 5 \text {. Allegro 3/4; } 6 \text {. Presto } \\
\text { (también Allegro) } 3 / 4\end{array}$ & A0751 \\
\hline 8. M. Delgado & $\begin{array}{l}\text { 1. Moderato 2/4; } 2 \text {. Andante (también Cantabile) 3/4; 3. Fuga (también Allegro) 4/4; 4. Andante 6/4; } 5 \text {. } \\
\text { Allegro 4/4; 6. Cantabile (también Largo) 3/4; 7. Allegro spiritoso (también Allegro, y Presto) 4/4 }\end{array}$ & A0752 \\
\hline 9. M. Delgado & $\begin{array}{l}\text { 1. Adagio 3/4, 2. Moderato 4/4; 3. Andantino 3/4; 4. Allegro moderato (también Allegro) } 4 / 4 ; 5 \text {. Moderato } \\
\text { (también Allegro, y Allegro moderato) } 2 / 4\end{array}$ & A0753 \\
\hline 10. M. Delgado & $\begin{array}{l}\text { 1. Allegro con spirito (también Presto) 3/4; 2. Allegro 4/4; 3. Andante (también Andantino) 3/4; } 4 \text {. } \\
\text { Presto } 4 / 4 ; 5 \text {. Amoroso (también Andante) } 2 / 4 ; 6 \text {. Allegro 6/8 }\end{array}$ & A0755 \\
\hline 11. M. Delgado & $\begin{array}{l}\text { 1. Allegro moderato (también Andante) } 3 / 4 ; 2 \text {. Andante (también Cantábile) } 3 / 4 ; 3 \text {. Allegro } 2 / 4 ; 4 \text {. Andante } \\
\text { (también Cantabile) } 3 / 4 ; 5 \text {. Allegro (también Presto) } 2 / 4\end{array}$ & A0756 \\
\hline
\end{tabular}




\begin{tabular}{|c|c|c|}
\hline 12. M. Delgado & $\begin{array}{l}\text { 1. Allegro } 3 / 4 ; 2 \text {. Allegro } 3 / 4 ; 3 \text {. Allegro } 4 / 4 ; 4 \text {. Andante (también Andante lento) } 4 / 4 ; 5 \text {. Allegro 4/4; } 6 \text {. } \\
\text { Cantabile (también Cantabile comodo, y Andante) } 3 / 4\end{array}$ & A0757 \\
\hline 13. M. Delgado & 1. Con spirito $3 / 4 ; 2$. Andante $4 / 4 ; 3$. Andante $3 / 4 ; 4$. Allegro $3 / 4 ; 5$. Allegro $4 / 4$ & A0758 \\
\hline 14. M. Delgado & 1. Allegro 4/4; 2 . Moderato $2 / 4 ; 3$. Allegro $4 / 4 ; 4$. Andante $3 / 4 ; 5$. Presto (también Allegro) $4 / 4$ & A0759 \\
\hline 15. M. Delgado & $\begin{array}{l}\text { 1. Allegro con spirito (también Allegro) } 4 / 4 ; 2 \text {. Andante } 3 / 4 ; 3 \text {. Allegro (Allegro moderato) } 2 / 4 ; 4 \text {. Allegro } \\
\text { con spirito } 4 / 4 ; 5 \text {. Aria cantábile } 3 / 4 ; 6 \text {. Allegro con spirito } 3 / 4\end{array}$ & A0760 \\
\hline 16. M. Delgado & $\begin{array}{l}\text { 1. Allegro 4/4; 2. Allegro 4/4; 3. Allegro (también Andante, y Allegretto) 3/4; 4. Presto 2/4; 5. Gracioso- } \\
\text { Presto 4/4 }\end{array}$ & A0761 \\
\hline 17. M. Delgado & $\begin{array}{l}\text { 1. Andante-Presto } 3 / 4 ; 2 \text {. Allegretto } 6 / 8 ; 3 \text {. Cantabile (también Andante) } 3 / 4 ; 4 \text {. Allegro } 4 / 4 ; 5 \text {. Andante } \\
\text { (también cantábile) } 3 / 4 ; 6 \text {. Presto (también Allegro) } 2 / 4\end{array}$ & A0762 \\
\hline 18. M. Delgado & & A0763 \\
\hline 19. M. Delgado & Ibid A0761 (1) & A0764 \\
\hline 20. M. Delgado & $\begin{array}{l}\text { 1. Andante brillante (también Andante) } 3 / 4 ; 2 \text {. Allegro } 4 / 4 ; 3 \text {. Andante } 4 / 4 ; 4 \text {. Maestoso (también Andante) } \\
3 / 4 ; 5 \text {. Andante (también Andante espresivo) } 2 / 4 ; 6 \text {. Allegro non presto } 3 / 4\end{array}$ & A0765 \\
\hline 21. J. M. Mora & $\begin{array}{l}\text { 1. Allegro } 4 / 4 ; 2 \text {. Andante } 6 / 8 ; 3 \text {. Allegro (también Vivo) 3/4; 4. Andante 3/4; 5. Vivo (también Allegro) } \\
6 / 8 ; 6 \text {. Andantino } 3 / 4\end{array}$ & A0903 \\
\hline
\end{tabular}

Tabla 3. Tempi de los versos de que aparecen en cada juego.

Como se puede observar en la tabla anterior, en los juegos de versos de Manuel Delgado nos encontramos con las mayores inconsistencias de tempi. Estos juegos, como he mencionado, fueron de los versos más usados, copiados y exportados en el México de principios del siglo XIX, por lo que las diferencias que encontramos en algunos corresponden a copias de partes (instrumentos) que se hacían por el mismo desgaste de los manuscritos o porque se le agregaban partes de instrumentos, como los versos de M. Aldana, en donde la nomenclatura cambia constantemente en un diálogo con la práctica. Ciertamente el cambio siempre coincide con un tiempo similar o equivalente, es decir; un andante puede también estar descrito como un cantabile, o un presto como un allegro, etc.

Otra cuestión que también llama la atención es que en muchos de los versos tenemos dos o tres tempi similares o iguales juntos, por lo que valdría la pena plantear a su vez si los versos instrumentales y orquestales se usaban siguiendo el orden que presentan los manuscritos o si se elegían en la práctica de acuerdo a aspectos tales como la variación, la duración, el carácter, etc. Aunque no podemos saber esto último con certeza, de acuerdo a las reconstrucciones que he elaborado todo indica que dos versos con el mismo tempi, ejecutados uno tras otro, pueden adaptarse mejor con la extensión de la música figura$\mathrm{da}^{35}$. Así, el orden de éstos, cualquiera que fuese a la hora de la ejecución, tenía que ensamblarse y alternarse con la agógica del canto llano, la cual, como sabemos gracias a documentos como el Diario Manual $^{36}$ o como en el Costumbrero ${ }^{37}$, entre otros,

35 RINCÓN (2016): 95-103.

36 PEÑARANDA (1751). En su tesis [MARÍN (2007): 780], Javier Marín apunta que una comparación del Diario Manval de la catedral con la Regla de coro y cabildo de la Catedral de Sevilla -los cuales cuentan con nueve años de diferencia-, muestra que casi un $80 \%$ de las festividades de mayor rango eran comunes en ambas instituciones. 37 MEX-Mc, GÓMEZ (1819). debía ser siempre "con mucho espacio y solemnidad, como el Rito lo pide", "guardando uniformidad", "ni rápido ni lento", "no con tanta solemnidad", etc. Mientras más solemne era la fiesta, el canto llano tenía que ser más y más lento.

Los juegos tienen, en su gran mayoría, de cinco a ocho versos instrumentales o versillos (según las tipologías organísticas), lo que muestra el canon que se estableció desde su surgimiento en el siglo XVI, hasta muy entrado el siglo XIX, debido a que es un número adaptable al número de versos de los salmos, siempre variable. Si tomamos en cuenta un oficio como las vísperas, los salmos que este oficio incluye son: Salmo 109 Dixit Dominus (10 versos); Salmo 110 Confitebor tibi (12 versos); Salmo 111 Beatus vir (11 versos); Salmo 112 Laudate pueri (10 versos); Salmo 113 In exitu Israel (29 versos). Algunos de éstos salmos solían sustituirse por otros tales como el Salmo 115 Credidi (10 versos); Salmo 116 Laudate Dominum (4 versos); Salmo 121 Laetatus sum (11 versos); Salmo 125 In convertendo (10 versos); Salmo 126 Nisi Dominus (8 versos); Salmo 147 Lauda Jerusalem (11 versos); etc. Y el cántico del Magníficat, que consta de 12 versos. Ciertamente, el número de versos instrumentales se adapta perfectamente al número de versos de los salmos. Probablemente el proceso compositivo consistiera en escribir un número de versos instrumentales adaptable a cada salmo en específico (como lo fue originalmente en los versos organísticos), y con el tiempo, estos versos se pudieron haber utilizado también aleatoriamente.

En la segunda década del siglo XVIII, la corriente del bajo continuo que compositores italianos como Ignacio Jerusalem y Santiago Billoni introdujeron en la Nueva España había sido desarrollada en la primera mitad del siglo por músicos de ópera napolitana que a su vez componían y estaban influenciados por la música sacra, tales como Leonardo Leo y Niccolo Porpora: texturas claras y armonías sencillas, "tañer a consonancias", que se deducen sobre la base de las tríadas primarias sin necesidad de un cifrado. 
Esta práctica del continuo italianizada contrastaba con la corriente que se desarrolló paralelamente en países como Alemania y Francia, e incluso en una Italia más elitista, como la de las cortes y la nobleza, en donde los compositores añadían y experimentaban con improvisaciones armónicas más complejas ayudándose del cifrado y la escritura codificada ${ }^{38}$. Fue en la primera mitad del siglo XVIII, precisamente con esta teorización del uso de la armonía como acompañamiento, donde empezaron a aparecer composiciones con obbligato, es decir, partes del teclado escritas en su totalidad ${ }^{39}$, escritura que no tardó en difundirse en todos los centros de música galante, incluido el México Independiente de la segunda mitad del XVIII, con com- positores como Manuel Delgado (*1747; $\uparrow 1819)$, y posteriores. No obstante, estas partes para órgano obbligato son partes con el acompañamiento escrito, lo que nos permite deducir, además, que el tipo de continuo que se hacía en la época era realmente muy sencillo ${ }^{40}$.

El término obbligato se empezó a usar también en partes de instrumentos consideradas esenciales, como en el juego de versos A0756 de M. Delgado. Y en este mismo despliegue de términos que contraponen sentidos surgió el ad libitum para partes de instrumentos opcionales y prescindibles, como podemos ver en el juego de versos A0752, del mismo Delgado.

\begin{tabular}{|c|c|c|c|}
\hline Compositor & Sig. & Obligado & \begin{tabular}{|l|} 
Bajo terminología \\
(No. de partes)
\end{tabular} \\
\hline 1. J. M. Aldana & A0685 & & Bajo (1) \\
\hline 2. J. M. Aldana & A0686 & 2 órganos obligados & Bajo duplicado \\
\hline 3. J. M. Aldana & A0687 & & Bajo (1) \\
\hline 4. M. Delgado & A0748 & & Bajo (1) \\
\hline 5. M. Delgado & A0754 & & Basso (1) \\
\hline 6. M. Delgado & A0750 & & Falta parte \\
\hline 7. M. Delgado & A0751 & & Basso (1) \\
\hline 8. M. Delgado & $\mathrm{A} 0752$ & Trompas y oboes ad libitum & Basso (1) \\
\hline 9. M. Delgado & A0753 & & Baxo (1) \\
\hline 10. M. Delgado & $\mathrm{A} 0755$ & & Bajo y violoncello (1) \\
\hline 11. M. Delgado & A0756 & Oboe y fagot obligado & $(1)$ \\
\hline 12. M. Delgado & A0757 & & Basso (2) \\
\hline 13. M. Delgado & $\mathrm{A} 0758$ & & Bajo y violoncello (1) \\
\hline 14. M. Delgado & $\mathrm{A} 0759$ & & Basso (1) \\
\hline 15. M. Delgado & $\mathrm{A} 0760$ & & Acompañamiento \\
\hline 16. M. Delgado & A0761 & & Violoncello solamente \\
\hline 17. M. Delgado & $\mathrm{A} 0762$ & Órgano obligado & Bajo y violoncello principal (1) Baxo (1) \\
\hline 18. M. Delgado & A0763 & & Falta \\
\hline 19. M. Delgado & A0764 & & $(1)$ \\
\hline 20. M. Delgado & $\mathrm{A} 0765$ & & Bajo violon (1), Bajo (1) \\
\hline 21. J. M. Mora & A0903 & & Bajos (2) \\
\hline
\end{tabular}

Tabla 4. Continuos, obligados, y partes ad libitum de los versos. (Entre paréntesis, número de partes que se han conservado).

En 1818, las Actas de Cabildo de la Catedral de México narran cómo el organista Juan José Ximénez se había negado a tocar un obligado debido a la dificultad que presentaba dicho manuscrito ${ }^{41}$, por lo que le reclamó al maestro de capilla Mateo Manterola, argumentando que era "cosa propia de

38 Algunos de los tratados europeos más importantes que hablan sobre el arte de tocar el continuo son, en Alemania: BACH (1753); en Italia: GASPARINI (1708); y en Francia: DELAIR (1690); así como los Principes de l'accompanement de D'ANGLEBERT (1689).

39 Ejemplos notables y pioneros de este tipo de escritura "obligada" los encontramos en la música de cámara de compositores tales como Johann Sebastian Bach, Georg Friedrich Händel, ElizabethClaude Jacquet de La Guerre, Jean-Joseph Cassanéa de Mondonville superiores", ${ }^{42}$ dudando incluso que dicho obligado perteneciera a la capilla. Ante esta situación, el cabildo pidió la opinión del antiguo maestro, Antonio de Juanas, quien expuso, de forma muy diplomática, su opinión acerca de la actitud que debían tener los organistas al enfrentarse con la escritura obligada ${ }^{43}$.

y Jean-Philippe Rameau, entre otros muchos. En España, la parte de órgano obligado más antigua que se ha encontrado es de 1722, parte de un villancico del Monte de Piedad, compuesto por José de Nebra.

40 Estos ejemplos de obligados de continuo muy sencillos los encontramos también a partir del siglo XVIII en las Catedrales Españolas. Ver: CASARES (1980): 63.

$41 \boldsymbol{M E X}-\mathbf{M c}$, Actas de cabildo, libro 68, fol 299r, 02.12.1817. 42 Ibid. 261. 
Aunque sabemos, por documentos relatores, que la improvisación de versillos ${ }^{44}$ convivió con la ejecución de los versos para instrumentos hasta finales del siglo XIX en la catedral de México y otras iglesias, es muy elocuente el hecho de que, mientras que en España los tratados, los manuscritos y los impresos que contienen versillos organísticos los encontramos en cualquier archivo musical, en la Nueva España y el México Independiente la ausencia de éstos es extrema, pues en todo el territorio solo se ha encontrado la presencia de un cuaderno con versos organísticos (en Oaxaca) [JOHNSON (2005)].

En España, junto con la introducción en el templo a principios del siglo XVIII de nuevos instrumentos tales como el violín, el oboe y la flauta travesera, se introduce también una nueva composición con énfasis en el leguaje idiomático para instrumentos. De donde los versos para pequeños conjuntos de instrumentos surgen en algunas catedrales españolas a mediados del siglo XVIII como variantes de los versos organísticos en una especie de intercambio entre la tradición y la innovación, pues en el caso español, incluso la escritura para instrumentos como las chirimías y los bajones absorbe un tipo de escritura idiomática, influenciada por la entrada de instrumentos como los violines, los oboes y la flauta travesera ${ }^{45}$. No obstante, a diferencia del Viejo Continente, en donde los versillos para instrumentos son la excepción y los versos organísticos la regla; la mayoría de las catedrales e iglesias pequeñas de la Nueva España y posteriormente del México Independiente contienen exclusivamente manuscritos de versos para conjuntos de instrumentos, "orquesta" y "gran orquesta", como les llamarán a partir de los versos de Manuel Delgado ${ }^{46}$.

En mi opinión, la ausencia de manuscritos o impresos de versillos para órgano no sólo está relacionada al hecho de que las fuentes transversales a la práctica de la improvisación, como los manuscritos de organistas elaborados como apoyo a la memoria, solían ser propiedad privada ${ }^{47}$; sino también a la

44 La terminología de algunos países católicos: versetti per organo en italiano, verset, en inglés y francés, y verso para órgâo en portugués.

45 En el libro editado por Antonio Ezquerro, único en España que contiene estas tipologías para instrumentos, se numeran tan solo 17 casos encontrados, en los cuales 14 son obras con acompañamiento escrito de órgano. De éstos, ocho se agrupan para una pareja de instrumentos aliento-madera iguales (dos oboes, dos flautas o dos bajones) y los seis casos restantes se conciben para un único instrumento: el bajón. EZQUERRO (2004).

46 Más información de estas tipologías en territorio mexicano se encuentra en: STANFORD (2002); TELLO, FRANCO \& MANÍ (2015)); DAVIES (2013); LAZOS (2012); GUERBEROF (2006); VARGA \& LAZOS (2013). Y por último: LAZOS (2013). O también: PAREYÓN (1997): 99-124; y ROUBINA (2009). Conviene aclarar que, en comparación con los otros géneros y formas, el corpus de versos con los que cuenta la Catedral de México es relativamente chico y se fue creando con contribuciones de músicos instrumentistas al servicio de la catedral o de las bibliotecas personales que éstos u otros músicos heredaban al archivo musical, como era costumbre de la época.

47 Como menciona Javier Marín: "A diferencia de los maestros de capilla, los instrumentistas disponían de sus propios libros y no estaban obligados a dejarlos en la catedral, aunque en ocasiones el Cabildo se interesó por su compra con la idea de ir formando un archivo, tal y como

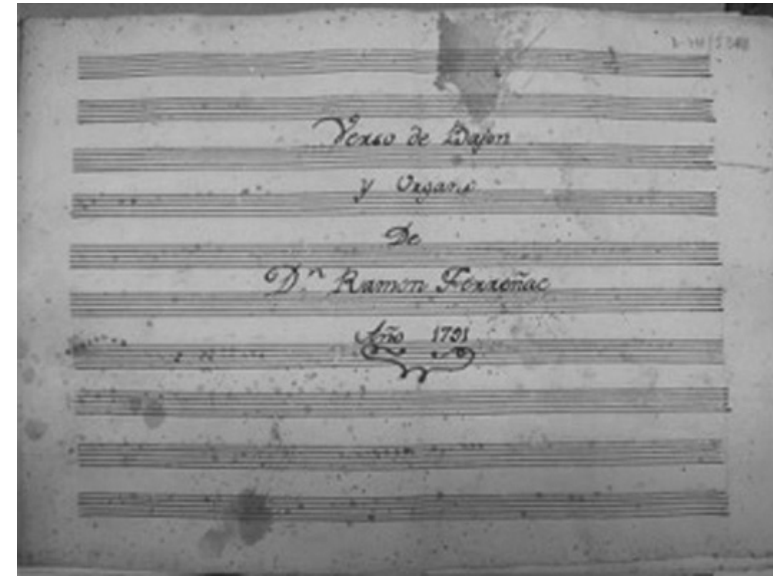

Fig. 5. Portada del Verso de bajón y órgano, de Ramón Ferreñac $(* 1763 ; \uparrow 1832)$,

El Pilar de Zaragoza. E-Zac, D-411/5358.

historia de la lectura y la descontextualización de las prácticas occidentales en las colonias. Viéndolo desde esta perspectiva, la casi ausencia de estas tipologías organísticas puede relacionarse a la gran emergencia de versos para conjuntos de instrumentos en el siglo XIX mexicano. Claro que en un caso como el de la Catedral de México se podría argumentar que dicha práctica de improvisación era un elemento obligatorio en la educación musical de las iglesias, y que incluso algunos de los organistas llegaron directamente del Viejo Mundo a trabajar en dicho recinto. No obstante, sabemos que cualquier contexto colonial en donde se ha introducido una cultura sin arraigo regional implica siempre una constante mutación de sentidos. Por tanto, una pregunta crucial al estudiar dicho género sería: ¿Cuál fue el impacto y el desarrollo de las prácticas de improvisación tales como los versillos para órgano e instrumentos en lugares como la Catedral de México, y más aún, en lugares con audiencia muy plural, como la Basílica de Guadalupe, en donde encontramos la cantidad mayor de juegos de versos para instrumentos? ${ }^{48}$. Al ser la música una herramienta de evangelización, sabemos que los que asistían a las celebraciones de la Iglesia en territorio novohispano y mexicano, es decir, los que repetían la misa e incluían en su imaginario sonoro dichas tipologías en alternancia pertenecían en gran parte a las poblaciones originarias. Interpretándolo desde la historia de la percepción, pienso que estas tipologías para conjuntos de instrumentos, especialmente los versos a partir de Manuel Delgado en adelante, pudieron captar y seducir mejor a la audiencia mexicana que el cultivo de la improvisación y de la composición de versillos en el órgano, relacionada a una práctica individual.

lo acredita la compra de libros con repertorio instrumental en 1578,1635 y 1745 . La propiedad privada de estas fuentes instrumentales explica el bajo número de manuscritos para ministriles y libros para órgano conservados actualmente en las catedrales...”. [MARÍN (2007): vol. 1, 547].

48 En la Basílica de Guadalupe se encuentran censados 74 juegos de versos. De acuerdo con: [GUERBEROF (2006)]. 
Aunque es muy delicado plantear una división historiográfica entre la Nueva España y el México Independiente, sobre todo en el ámbito musical perteneciente al ritual, la historia local de los versos para conjuntos de instrumentos nos enseña cómo el aspecto sonoro del templo se vio cada vez más afectado por los sucesos sociales externos relacionados a la historia particular de México. De hecho, para comprender las postrimerías del Virreinato de la Nueva España y el porqué de los movimientos independentistas, cabe también mencionar que ya desde 1786 se había producido una de las crisis agrícolas más grandes de su historia, provocando no sólo escasez y desempleo, sino también una hambruna en la que murieron cerca de 300.000 personas ${ }^{49}$. Además, propio del modernismo y la normativización en la Nueva España fue la distinción moralizante y elitista de las "clases altas" (denominación europea que surgió en aquella época) aplicada a las "clases bajas" que, si bien sacaba a las poblaciones originarias de una gran ambigüedad al tiempo que los alfabetizaba y castellanizaba, lo era también para tomar provecho de esto ${ }^{50}$. Como menciona el historiador francés S. Gruzinsky,

\begin{abstract}
"el desarrollo de un cristianismo indígena en el siglo XVIII también es producto de la evolución global de la sociedad colonial y, en particular, de la Iglesia. Al parecer, aunque fue hasta fines del siglo XVIII cuando algunos hablantes de las culturas originarias empezaron de manera regular a recibir el sacerdocio [...], hacia mediados del siglo XVIII, la Nueva España ya contaba con al menos unos 50 sacerdotes indígenas" ${ }^{51}$.
\end{abstract}

En los versos, esto último es más evidente en las iglesias de las localidades pequeñas, como el caso de la parroquia de Santiago Chazumba en Oaxaca, en donde encontramos versos con instrumentos como el saxhorno, el bombardón o la gran cassa; típicos de las bandas de pueblo, o la Basílica de Guadalupe, lugar de peregrinación que recibía constantemente fieles de un extracto social muy diverso.

Manuel Delgado, José María Aldana y Mariano Mora pertenecieron a una generación de músicos que convertiría en un punto y aparte en la forma de concebir la música dentro y fuera del ritual. Si el concepto de política cobró vida en los movimientos independentistas que se forjaron en la primera mitad del siglo XIX, lo fue también a base de procesos complejísimos de descontextualización y aculturación que pocas veces se toman en cuenta en el debate de la música escrita de la musicolo-

49 A 1785-1786 se le conoce como el "año del hambre".

50 "En 1780, los curas informaron que los censos no podían ser exactos en la ciudad de México 'por las muchas familias volantes que no tienen casa, ni residencia fija, viviendo y durmiendo en las calles y plazas' y que estaban convencidas (con justa razón) de que el censo estaba planeado para imponer 'una contribución' o para 'alistarlos para soldados": LEMPÉRIÈRE (2013): 195.

51 GRUZINSKI (2013): 261. Se tienen registrados casos de maestros de capilla pertenecientes a los pueblos originarios desde principios del siglo XVII, como el zapoteco Juan Matías (*1618c; †1665) en Oaxaca; además del casos de los ministriles, que tañeron instrumentos desde los primeros años de la conquista. gía que estudia las fuentes americanas, tanto dentro como fuera del ritual. Tras ellos, los nuevos compositores de versos instrumentales serán tecladistas, ejecutantes de varios instrumentos de aliento y/o de cuerdas, cantantes, teóricos, profesores en academias emergentes fuera del dominio de la Iglesia, directores de asociaciones filarmónicas, y demás músicos que se irán diversificando y adaptando a los cambios y concepciones de la época.

\section{BIBLIOGRAFÍA}

Bach, Carl Philipp Emanuel, Versuch über die wahre Art das Clavier zu spielen. Berlín, Im Selbstverlag, Christian Friedrich Henning, 1753.

Bonastre i Bertran, Francesc; Martín Moreno, Antonio; y Climent Barber, Josep (eds.), Pedro Rabassa: Guía Para los Principiantes; que dessean Perfeycionarse en la Composicion de la Mussica. Bellaterra, Universitat Autònoma de Barcelona, Institut Universitari de Documentació i d'Investigació Musicològiques “Josep Ricart i Matas”, 1990.

Brown, Clive, Classical and Romantic Performing Practice, 1750-1900. Oxford, Oxford University Press, 1999.

Casares Rodicio, Emilio, La música en la Catedral de León: maestros del siglo XVIII y catálogo musical. León, Centro de Estudios e Investigación San Isidoro, Archivo Histórico Diocesano, 1980.

D'Anglebert, Jean-Henri, Pièces de clavecin avec la manière de les jouer. Diverses chaconnes, ouvertures et autre airs de M. de Lully, mis sur cet instrument. Quelques fugues pour l'orgue et les principes de l'accompagnement. Livre premier. París, chez l'auteur, 1689.

Davies, Drew Edward, Catálogo de música del Archivo Histórico de la Arquidiócesis de Durango. México, UNAM, IIE, ADABI, 2013.

Delair, Denis, Traité d'accompagnement pour le théorbe, et le clavecin. París, l'auteur, 1690.

Diario de México (13.10.1805).

Diario de México (17.12.1806).

Diario de México (14.05.1807).

Diario de México (24.10.1807).

Enríquez Rubio, Lucero; Davies, Drew Edward; y Cherñavsky, Analía, Catálogo de obras de Música del Archivo del Cabildo Catedral Metropolitano de México. (I. Villancicos y cantadas. II. Vísperas, antífonas, salmos, cánticos y versos instrumentales). 2 vols. Ciudad de México, UNAM, CONACULTA, INBA, 2014.

Ezquerro Esteban, Antonio, Música instrumental en las catedrales españolas en la época ilustrada. Barcelona, Departamento de Musicología, Institución "Milà i Fontanals", Consejo Superior de Investigaciones Científicas, col. "Monumentos de la Música Española, LXIX", 2004.

Gasparini, Francesco, L'armonico pratico al cimbalo. Venecia, Bortoli, 1708.

Goehr, Lydia, The Imaginary Museum of Musical Works. An Essay in the Philosophy of Music. Nueva York, Oxford University Press, 2007. 
Gómez, Vicente, El Costumbrero: Ceremonias que se practican en esta Santa Iglesia en el Coro, como en el altar en todo el año. Según los estatutos de erección mandatos del $\mathrm{V}$ Cabildo y costumbres loables; y otras cosas pertenecientes al servicio de esta Santa Iglesia. Con varias cosas que han acontecido. Por el subchantre Prestibero Vicente Gómez, Año 1819. Ms. México, 1819.

Gruzinski, Serge, La colonización de lo imaginario. Sociedades indígenas y occidentalización en el México español. Siglos XVI-XVIII. México, Fondo de Cultura Económica, 2013.

Guerberof Hahn, Lidia, Archivo Musical / Catálogo, Insigne y Nacional Basílica de Santa María de Guadalupe. México, Basílica de Guadalupe, 2006.

Hernández Monterrubio, Mauricio, "José Manuel Aldana: hacia un nuevo panorama del siglo XVIII", Heterofonía, XXXIV/125 (julio-diciembre 2001), 9-30.

Johnson, Calvert (ed.), Cuaderno de Tonos de Maitines de Sor María Clara del Santísimo Sacramento. Carolina del Norte, Wayne Leupold Editions, 2005 [ed. bilingüe].

Lazos, John, Catálogo musical del Archivo Histórico Diocesano de la Catedral de San Cristóbal de Las Casas, Chiapas I Music catalogue of the Historical Diocesan Archives at the Cathedral of San Cristóbal de Las Casas, Chiapas. Frankfurt, RISM Series A/II Musical manuscripts after 1600, 2012.

Lazos, John, Catálogos de los acervos musicales de las parroquias de Santiago Chazumba y de San Cristobal de Suchixtlahuaca, en la Sierra Mixteca de Oaxaca. México, RISM Musical Sources in MEX-SCHamp, 2013.

Lempérière, Annick, Entre Dios y el rey: la república. La ciudad de México de los siglos XVI al XIX: México, Fondo de Cultura Económica, 2013.

Marín López, Javier, Los libros de polifonía de la Catedral de México. 2 vols. Madrid, Sociedad Española de Musicología, Universidad de Jaén, 2012.

Marín López, Javier, Música y músicos entre dos mundos. La Catedral de México y sus libros de polifonía, siglos XVIXVIII. 3 vols. Tesis doctoral, Granada, Universidad de Granada, 2007.

Mier, Raymundo, Introducción al análisis de textos. México, Trillas/UNAM, 1990.

Miranda Pérez, Ricardo, "Reflexiones sobre el clasicismo en México (1770-1840)", Heterofonía, XXX/116-117 (1997), 39-50.

Nassarre, fray Pablo, Escuela música según la práctica moderna. 2 vols. Zaragoza, Herederos de Diego de Larumbe, 1724 y 1723 .

Pareyón, Gabriel: "Sumario histórico de la música en la Catedral de Guadalajara", Heterofonía, 116-117 (1997), 99124.

Peñaranda, Juan de, El DIARIO MANVAL DE LO QVE EN / Esta Santa Yglesia Cathe / dràl Metropolitana de México se / Practica y Observa, en su Altar, Choro, / y demás que le ès debido hacer en to= / dos, y cada uno de los días del Año. / Arreglado en todo â su Ereccion, / Estatutos, Cartilla, Constumbres, Fun- / daciones y Rubricas. Para su màs $=/$ Puntual ê imbiolable Ôbserv.a / Hecho $=/$ Por el M. Yll.e y Ve. Sor Dean y Cav.do / Año de 1751. México, Archivo del Cabildo Catedral Metropolitano de México, Serie Ordo, Libro 2, 1751.

Powers, Harold, "From Psalmody to Tonality", en [Judd, Cristle Collins (ed.)] Tonal Structures in Early Music. Nueva York, Garland Pub., 1998: 274-340.

Rincón Serratos, Jazmín, "Los versos instrumentales de Ignacio Jerusalem y Stella: vestigios de un discurso sonoro en la Catedral de México", Anales del Instituto de Investigaciones Estéticas, XXXVI/105 (2014), 95-126.

Rincón Serratos, Jazmín, El verso instrumental: historia y función de un género musical en la Catedral de México. Tesis Doctoral, México, Universidad Nacional Autónoma de México, 2016.

Roubina, Evguenia, Obras instrumentales de José Manuel Delgado y José Francisco Delgado y Fuentes. México, Ediciones Eón, 2009.

Sanabria Varga, Patricia y Lazos, John, Catálogo del Archivo Histórico Musical de la Parroquia El Sagrario de la Catedral de Tulancingo. México, Adabi de México, 2013.

Santa María y Fuentes, fray Francisco de, Dialectos músicos, en que se manifiestan los más principales elementos de la armonía, Madrid, Joaquín Ibarra, 1778.

Soler Ramos, Antonio, Llave de la modulación y antigüedades de la música. Madrid, Joaquín Ibarra, 1762.

Stanford, Thomas E., Catálogo de los acervos musicales de las catedrales metropolitanas de México y Puebla de la Biblioteca Nacional de Antropología e Historia y otras colecciones menores. México, Instituto Nacional de Antropología e Historia, 2002.

Tello Malpartida, Aurelio; Franco Gutiérrez, Dalila; y Maní Andrade, Abel: Archivo de Música del Venerable Cabildo de la Catedral de Puebla; Catálogo y Apéndice biográfico de compositores novohispanos. México D.F., CONACULTA-INBA-CECAP, 2015.

Torres Martínez Bravo, José de, Reglas generales de acompañar, en órgano, clavicordio, y harpa, con solo saber cantar la parte, o un baxo en canto figurado. Madrid, Imprenta de Música, 1702-1736.

Vargas y Guzmán, Juan Antonio de, Explicación para tocar la guitarra de punteado por música o cifra, y reglas útiles para acompañar con ella la parte del bajo. Ms. Veracruz, 1776.

Weber, William, The Great Transformation of Musical Taste. Concert Programming from Haydn to Brahms. Nueva York, Cambridge University Press, 2008. 